\title{
Addition of Olive Oil to Dairy Ewe Diets: Effect on Milk Fatty Acid Profile and Animal Performance
}

\author{
P. Gómez-Cortés, ${ }^{*}$ P. Frutos,† A. R. Mantecón, † M. Juárez, ${ }^{*}$ M. A. de la Fuente, ${ }^{\star 1}$ and G. Hervás† \\ *Instituto del Frío (Consejo Superior de Investigaciones Científicas), José Antonio Novais 10, Ciudad Universitaria s/n, 28040 Madrid, Spain \\ †Estación Agrícola Experimental (Consejo Superior de Investigaciones Científicas), Finca Marzanas, 24346 Grulleros, León, Spain
}

\begin{abstract}
The effects of ruminant diet supplementation with linoleic or different polyunsaturated fatty acids (FA) have been well documented. Less abundant information, however, exists on the effects of incorporating monounsaturated FA, such as oleic acid, on lipid metabolism or animal performance. The purpose of this work was to assess the effects of feeding dairy ewes a diet supplemented with high levels of olive oil (OO) on milk yield and composition, paying particular attention to the FA profile. Twenty-four Assaf ewes were fed ad libitum with 2 diets, control or supplemented with $6 \%$ OO (2 lots of 6 animals per diet) for 4 wk. Milk yield and composition and dry matter intake were recorded weekly. Milk FA composition was determined by gas chromatography and conjugated linoleic acid profile by silver ion HPLC. Milk yield increased in ewes receiving $\mathrm{OO}$, with no differences in dry matter intake. The OO diet decreased the milk protein percentage but increased the milk fat, protein, and total solids yield. Medium-chain saturated FA (C10:0 to C16:0) content was reduced with $\mathrm{OO}$ supplementation, whereas C18:0 and cis-9 C18:1 content increased. Leaving aside trans11, most trans C18:1 isomers, mainly trans-10, increased in supplemented ewes. The main conjugated linoleic acid isomer (cis-9, trans-11 C18:2) decreased with $\mathrm{OO}$ supplementation, whereas trans-7, cis-9 and trans-9, cis-11 C18:2 exhibited a remarkable increase. These results support the argument that the supplementation of ewe diets with high levels of $\mathrm{OO}$ does not have any detrimental effects on animal performance but substantially modifies the FA profile.
\end{abstract}

Key words: oleic acid, olive oil, conjugated linoleic acid, monounsaturated fatty acid

\section{INTRODUCTION}

Many fat sources can be used to supplement the diet of ruminants to increase net dietary energy or modify

Received December 17, 2007.

Accepted April 8, 2008.

${ }^{1}$ Corresponding author: mafl@if.csic.es milk fat content and its fatty acid (FA) profile. The effect of dairy cow nutrition on the production and composition of milk has been extensively reviewed (Mir et al., 2003; Walker et al., 2004). Plant oils from different oilseeds have different FA compositions and accordingly have a different effect on milk FA profile. Modification of this profile is significantly affected by the extensive metabolism of the lipid diet that occurs in the rumen and mammary gland. Moreover, the effects of supplementation with linoleic or different polyunsaturated FA (PUFA) in dairy cow diets have generally been well described (Chilliard et al., 2003; Chilliard and Ferlay, 2004; Dhiman et al., 2005).

In dairy ewes, most attention has also focused on lipid supplements enriched in PUFA from oilseeds or plant and marine oils (Pulina et al., 2006; Sanz-Sampelayo et al., 2007). Oleic acid is the major monounsaturated FA (MUFA) in ruminant feeds, but its conversion in animals is uncertain. Although research has been undertaken to assess the effect of incorporating protected MUFA in the form of calcium soaps in rations (Pulina et al., 2006) on lipid metabolism or animal performance, less information has been reported on unprotected olive oil (OO) supplementation in sheep. According to some accounts, oleic acid conversion by rumen microorganisms yields only stearic acid without the formation of any intermediates (Kellens et al., 1986; Harfoot and Hazlewood, 1997), whereas in vitro batch culture studies reported the conversion of oleic acid to a variety of trans monoenes (Mosley et al., 2002; AbuGhazaleh et al., 2005).

The use of high doses of oil in the diet was not recommended in ruminants, particularly ewes, because it apparently inhibits rumen microbial activity and could affect milk yield and composition (Jenkins, 1993). High concentrations of fat added to sheep rations seemed to decrease the fermentative activity of the rumen microbiota, thus reducing the positive effect of the greater energy density of the diet (Broudiscou et al., 1994). Fortunately, more recent research has demonstrated the feasibility of incorporating high levels of unprotected oil in sheep diet. Diets supplemented with soybean oil modified the FA profile of milk fat but did not 
Table 1. Ingredients and chemical composition of control and olive oil (OO)-supplemented diets

\begin{tabular}{lrr}
\hline & \multicolumn{2}{c}{ Diet } \\
\cline { 2 - 3 } Item & Control & OO \\
\hline Ingredient, g/kg of DM & & \\
Dehydrated alfalfa hay & 200.0 & 188.0 \\
Beet pulp & 90.0 & 84.6 \\
Whole corn grain & 250.0 & 235.0 \\
Whole barley grain & 150.0 & 141.0 \\
Soybean meal & 200.0 & 188.0 \\
Olive oil ${ }^{1}$ & 0.0 & 60.0 \\
Molasses & 65.0 & 61.1 \\
Salts & 40.0 & 37.6 \\
Minerals and vitamins & 5.0 & 4.7 \\
Composition, g/kg of DM & & \\
OM & 104.4 & 100.7 \\
CP & 166.9 & 163.0 \\
NDF & 230.1 & 227.4 \\
ADF & 128.6 & 124.1 \\
Ether extract & 24.6 & 66.4 \\
Fatty acid composition, \% total fatty acids & 17.8 & 12.6 \\
C16:0 & 3.4 & 3.6 \\
C18:0 & 30.1 & 69.0 \\
cis-9 C18:1 & 1.0 & 2.1 \\
Other C18:1 & 44.1 & 11.0 \\
C18:2 & 0.5 & 0.4 \\
C18:3 & 2.6 & 1.2 \\
C20:0 & & \\
\hline & &
\end{tabular}

${ }^{1}$ Olive oil contained (\% total fatty acids) C16:0 (11.5), C18:0 (3.5), cis-9 C18:1 (76.3), other C18:1 (2.2), C18:2 (5.3), C18:3 (0.7), and C20:0 (0.4).

have any detrimental effects on animal performance (Mele et al., 2006; Gómez-Cortés et al., 2008). The purpose of this study was to evaluate the effects of feeding dairy ewes with a diet supplemented with a high level of OO $(6 \%)$ on milk yield and composition, paying particular attention to the FA profile.

\section{MATERIALS AND METHODS}

\section{Animals and Experimental Diets}

Twenty-four primiparous Spanish Assaf ewes (body weight: $70.9 \pm 1.70 \mathrm{~kg}$ ) in mid-lactation were used. The ewes were distributed in 4 lots of 6 animals, balanced for milk yield and live weight, and allocated at random to 2 experimental treatments ( 2 lots per treatment): control and supplemented with OO.

The ewes were milked at about 0830 and $1830 \mathrm{~h}$ in a $1 \times 12$ stall-milking parlor (DeLaval, Madrid, Spain). The experiment lasted for a total of $5 \mathrm{wk}$ and was carried out in accordance with the Spanish Royal Decree $1201 / 2005$ for the protection of animals used for experimental purposes. The diets consisted of a total mixed ration, including molasses to avoid selection of dietary components, based on alfalfa hay and concentrate supplemented with 0 (control) or $60 \mathrm{~g}$ of OO/ $\mathrm{kg}$ of DM. The ingredients and chemical composition of the experimental diets are given in Table 1. For the first week of the trial (adaptation week), all the animals received the control diet. Fresh diets were offered daily ad libitum at about 0900 and $1900 \mathrm{~h}$.

\section{Measurements, Sample Collection, and Chemical Analysis}

Samples of offered and refused diets were collected once a week, stored at $-30^{\circ} \mathrm{C}$, and then freeze-dried. The intake was thus recorded weekly for each experimental lot. Procedures described by AOAC (2006) were used to determine the DM, OM, Kjeldahl N, and ether extract. Crude protein was calculated as $\mathrm{N} \times 6.25$. Neutral detergent fiber and $\mathrm{ADF}$ were determined by the methods described by Goering and Van Soest (1970) and Van Soest et al. (1991). Neutral detergent fiber was assayed with $\alpha$-amylase and sodium sulfite.

Individual milk yield was recorded once a week (d 0 , $7,14,21$, and 28). Milk samples for the determination of fat, protein, and total solid concentrations were also collected weekly from each animal. Fat, protein, and total solid concentrations were determined (AOAC, 2006) in samples treated with natamycin, by infrared spectrophotometry using a Milko-Scan 255 A/S N (Foss Electric, Hillerød, Denmark).

\section{FA Analysis}

Fatty acid composition was determined in untreated samples of milk from each experimental lot, composited according to individual milk yield. Milk fat was extracted following the Luna et al. (2005) procedure. Fatty acid methyl esters (FAME) were prepared by base-catalyzed methanolysis of the glycerides according to ISOIDF (2002). The FAME analysis was performed on a gas-liquid chromatograph (Agilent $6890 \mathrm{~N}$ Network System, Palo Alto, CA) with an auto injector onto a CPSil 88 fused silica capillary column $(100 \mathrm{~m} \times 0.25 \mathrm{~mm}$, Varian, Middelburg, the Netherlands) according to Gómez-Cortés et al. (2008).

Correction factors of FAME were determined by analyzing butter oil of a known FA profile with certified values (CRM 164; European Community Bureau of Reference, Brussels, Belgium). Each conjugated linoleic acid (CLA) peak was identified by comparing it with standards from Nu-Chek Prep Inc. (Elysian, MN): pure CLA methyl ester isomers (cis-9, trans-11 and trans10, cis-12 C18:2) and a mixture of trans-8, cis-10; cis9, trans-11; trans-10, cis-12; cis-11, trans-13 C18:2 with small amounts of a variety of all cis and all trans C18:2 isomers.

The preparation of dimethyloxazoline (DMOX) derivatives from FAME was based on the Fay and Richli (1991) procedure. The CLA DMOX derivatives were 
separated with the same column on an Agilent GC chromatograph (model 6890N) connected to a mass spectrometer detector (MS 5973N). The filament trap current was $400 \mu \mathrm{A}$ at 70 electronvolts. The DMOX derivatives were injected splitless into the same column in the following conditions: initial oven temperature was $75^{\circ} \mathrm{C}$ for 2 min after injection, then temperature was programmed at $5^{\circ} \mathrm{C} / \mathrm{min}$ to $180^{\circ} \mathrm{C}$ and held there for 30 min, and then temperature was programmed at $5^{\circ} \mathrm{C} /$ min to $220^{\circ} \mathrm{C}$ and held there for $30 \mathrm{~min}$. The column inlet pressure was set at $28.7 \mathrm{kPa}$.

Silver ion HPLC separation of CLA methyl esters was carried out using an HPLC (model SPE-MA10AVP, Shimadzu, Kyoto, Japan) equipped with a diode array detector operated at $233 \mathrm{~nm}$. Three ChromSpher 5 Lipid analytical silver-impregnated columns $(250 \mathrm{~mm} \times 4.6$ $\mathrm{mm}$ i.d. stainless steel; $5 \mu \mathrm{m}$ particle size; Varian) were used in series. The mobile phase was $0.1 \%$ acetonitrile and $0.5 \%$ diethyl ether in hexane and was operated isocratically at a flow rate of $1.0 \mathrm{~mL} / \mathrm{min}$. The chromatographic areas for 7-9, 8-10, and 9-11 CLA were used for comparison with the peak area of the 3 isomers from the gas chromatogram. The amounts of the other CLA isomers were calculated from their silver ion HPLC areas relative to the area of the main positonal isomer 9-11. The results were expressed as absolute values in milligrams per gram of fat.

\section{Statistical Analyses}

Data on DM intake, milk yield and composition, as well as FA composition and CLA profile were analyzed by repeated-measurement analysis (Wang and Goonewardene, 2004), using the MIXED procedure of SAS (SAS Institute Inc., Cary, NC) and assuming a compound symmetric structure on the basis of Schwarz's Bayesian information model fit criteria. The statistical model included the fixed effects of diet (D), time (T), their interaction $(\mathrm{D} \times \mathrm{T})$, and the initial record measured at 0 wk (covariate). For all data collected either individually (milk yield and composition) or per lot (DM intake, FA composition, and CLA profile), the lot was nested within the diet to contrast the effect of the $\mathrm{OO}$ supplementation. Pearson correlation coefficients $(r)$ were generated for associations between FA using the CORR procedure of SAS. Regression analyses were performed using the REG procedure of SAS. Significance was considered at $P<0.05$, and differences of $P>0.05$ to $P<0.10$ were discussed as trends. Least squares means (adjusted for the covariance) are reported throughout.

\section{RESULTS}

As shown in Table 2, supplementation with $\mathrm{OO}$ did not affect DM intake but increased milk yield $(P<0.05)$ and tended to increase fat, protein, and total solid yield $(P<0.10)$. Milk fat and total solid content was not modified by the type of diet. However, protein content decreased in milk from ewes receiving the $\mathrm{OO} \operatorname{diet}(P$ $<0.01$ ).

Table 3 shows the FA profile of milk fat from ewes fed the control and lipid-supplemented rations. Dietary supplementation with $\mathrm{OO}$ resulted in marked modifications in milk FA composition compared with the control diet throughout the period monitored. Feeding 6\% OO characterized by greater MUFA contents (Table 1) significantly increased this FA class in milk to the detriment of saturated FA. Decreases in C10:0, C12:0, C14:0, and C16:0 percentages were particularly remarkable $(P<0.05)$. It was found that $\mathrm{C} 18: 0$ and most C18:1 FA isomers increased $(P<0.01)$ when $\mathrm{OO}$ was included in the diet, whereas other cis-9 monoenes $(14: 1,16: 1,17: 1$, and 20:1) significantly decreased as a consequence of lipid supplementation (Table 3). Most trans C18:1, mainly trans-10, increased (Figure 1). Olive oil diet caused a 5-fold enrichment in this isomer, whereas trans-11 C18:1 (vaccenic acid, VA) did not increase in ewe milk fat with lipid supplementation.

Percentages of linoleic acid diminished with the supplemented diet $(P<0.01)$, whereas those of other nonconjugated $\mathrm{C} 18: 2$ isomers did not exhibit any significant changes. A decrease was observed for cis-9, trans-11 C18:2 (rumenic acid, RA; Table 3). After RA, trans-7, cis-9 isomer was the second most abundant CLA isomer (Table 4). As can be seen in Tables 3 and 4, this isomer and trans-9, cis-11 C18:2 increased remarkably with OO supplementation. As for the evolution of the other CLA isomer levels, different behaviors were observed. Finally, several $\mathrm{D} \times \mathrm{T}$ interactions $(P<0.05)$ were observed for several FA such as most of the trans MUFA (Table 3) and some CLA isomers (Table 4).

\section{DISCUSSION}

\section{Milk Yield and Composition}

Supplementation with OO increased milk yield (Table 2), which was probably accounted for by a greater energy content of the oil-supplemented diet and not by a greater DM intake $(P>0.10)$. This increase in milk yield would explain the tendency $(P<0.10)$ toward a greater fat, protein, and total solid yield. On the other hand, the protein content was reduced by the OO, which has often been observed when dairy ewes are supplemented with lipids (Pulina et al., 2006), and it may be due to insufficient amino acids in the mammary gland necessary to accompany the increased milk yield (Gaynor et al., 1994).

In sheep, milk fat content and yield are not generally reduced but are often increased by vegetable oil supple- 
Table 2. Mean effects of diet supplementation with olive oil (OO) on DMI, milk yield, and milk composition

\begin{tabular}{|c|c|c|c|c|c|c|}
\hline \multirow[b]{2}{*}{ Item } & \multicolumn{2}{|c|}{ Treatment ${ }^{1}$} & \multirow[b]{2}{*}{ SED } & \multicolumn{3}{|c|}{$P<^{2}$} \\
\hline & Control & $\mathrm{OO}$ & & D & $\mathrm{T}$ & $\mathrm{D} \times \mathrm{T}$ \\
\hline DMI, kg/d & 2.33 & 2.46 & 0.298 & 0.75 & 0.04 & 0.26 \\
\hline \multicolumn{7}{|l|}{ Yield, g/d } \\
\hline Milk & 1,713 & 1,946 & 20.7 & 0.04 & 0.61 & 0.51 \\
\hline Fat & 87.8 & 102.9 & 1.74 & 0.07 & 0.66 & 0.90 \\
\hline Protein & 84.5 & 91.7 & 0.94 & 0.08 & 0.88 & 0.81 \\
\hline Total solids & 273.2 & 311.2 & 3.90 & 0.05 & 0.93 & 0.89 \\
\hline \multicolumn{7}{|c|}{ Composition, \% } \\
\hline Fat & 5.39 & 5.27 & 0.083 & 0.62 & 0.12 & $<0.01$ \\
\hline Protein & 4.96 & 4.77 & 0.001 & $<0.01$ & 0.11 & 0.05 \\
\hline Total solids & 16.23 & 15.99 & 0.061 & 0.24 & $<0.01$ & $<0.01$ \\
\hline
\end{tabular}

\footnotetext{
${ }^{1}$ Refers to diets containing 0 (control) or $60 \mathrm{~g}$ of OO/kg of DM.

${ }^{2}$ Probability of significant effects due to diet supplementation with olive oil (D), time on diet (T), and their
} interaction $(\mathrm{D} \times \mathrm{T})$.

mentation (Chilliard et al., 2003; Pulina et al. 2006; Sanz-Sampelayo et al., 2007). In cow milk, some trans FA (trans-10 C18:1, trans-10, cis-12 C18:2, and trans-9, cis-11 C18:2) have been proposed as milk fat synthesis inhibitors. The current study would support the idea that factors other than trans-10 C18:1 are probably involved in regulating mammary lipogenesis in ewes. Very recent research in cow milk (Lock et al., 2007), which provides no support for the idea that changes in rumen production of trans-10 C18:1 play a role in the regulation of FA synthesis during diet-induced milk fat depression, would be in agreement with the current results (Table 3).

The increase in trans-10, cis-12 and trans-9, cis-11 C18:2 due to OO supplementation did not decrease ewe milk fat content (Table 2), contrary to observations in cows (Griinari and Bauman, 1999; Shingfield et al., 2006; Gama et al., 2008). An argument to explain these discrepancies between species could be based on the low amounts of these trans FA in ewe milk fat. A synthetic CLA supplement containing trans-10, cis-12 C18:2 reduced milk fat synthesis in lactating sheep (Lock et al., 2006), indicating that the milk fat depression mechanism in sheep is apparently similar to that of cows. Following this line, Pulina et al. (2006) argued that sheep would probably be less prone to milk fat depression because of their ability to ruminate and have normal rumen function, even when fed finely ground diets that cause rumen acidosis in cows. However, definitive evidence to clarify this controversy has to be obtained.

\section{Saturated FA}

The potential for decreasing saturated FA from C10:0 to $\mathrm{C} 16: 0$ in milk is very great with lipid supplementation. This FA group is produced by de novo lipogenesis in the mammary gland. Part of the reduction in de novo
FA synthesis could be due to a greater uptake to the mammary gland of dietary and ruminally derived longchain FA. These FA would compete for esterification with medium-chain FA synthesized in the mammary gland, which may lead to feedback inhibition of lipogenesis enzymes (Palmquist et al., 1993). This effect would be more marked when FA are more unsaturated and contain more trans double bonds (Chilliard and Ferlay, 2004). Thus, when the bioavailability of C18 FA increases as a result of increased dietary intake, C10:0 to $\mathrm{C} 16: 0$ de novo synthesis decreases as does their (C10:0 to C16:0) concentration in milk. Fewer mediumchain saturated FA and more C18:1 and C18:0 were also reported in the milk of ewes fed a diet supplemented with olive cake (Chiofalo et al., 2004). In dairy cows, supplementation of the control diet with rapeseed, which is rich in oleic acid, resulted in lower concentration of the saturated FA C10:0 to C16:0 and greater levels of stearic and oleic acids compared with the control diet (Jaros et al., 2001; Collomb et al., 2004b).

\section{MUFA}

The increase in C18:0 in milk from the supplemented diet (Table 3) must be attributed to the FA intake. Stearic acid secretion in milk can be increased either by increasing stearic acid intake or by supplementing with C18 unsaturated FA, because they can be completely hydrogenated in the rumen. Also cis-9 C18:1 can either be the result of the diet or the action of mammary $\Delta^{9}$-desaturase on C18:0. When unprotected vegetable oils rich in oleic acid are given to ruminants, the main response will be an increase in the stearic acid produced in the rumen, which is then partly converted into oleic acid in the udder (Chilliard and Ferlay, 2004). In cows, approximately $40 \%$ of C18:0 taken up 
Table 3. Mean effects of diet supplementation with olive oil (OO) on milk fatty acid profile ( $\mathrm{g} / 100 \mathrm{~g}$ of fatty acids)

\begin{tabular}{|c|c|c|c|c|c|c|}
\hline \multirow[b]{2}{*}{ Item } & \multicolumn{2}{|c|}{ Treatment $^{1}$} & \multirow[b]{2}{*}{ SED } & \multicolumn{2}{|c|}{$P<^{2}$} & \multirow[b]{2}{*}{$\mathrm{D} \times \mathrm{T}$} \\
\hline & Control & $\mathrm{OO}$ & & $\mathrm{D}$ & $\mathrm{T}$ & \\
\hline \multicolumn{7}{|l|}{ Saturated } \\
\hline C4:0 & 4.37 & 4.59 & 0.324 & 0.51 & 0.04 & 0.81 \\
\hline C6:0 & 3.34 & 3.14 & 0.121 & 0.15 & $<0.01$ & 0.04 \\
\hline C8:0 & 2.78 & 2.77 & 0.110 & 0.92 & 0.02 & $<0.01$ \\
\hline C10:0 & 9.00 & 6.64 & 0.199 & $<0.01$ & 0.03 & $<0.01$ \\
\hline $\mathrm{C} 12: 0$ & 4.90 & 3.22 & 0.072 & $<0.01$ & $<0.01$ & $<0.01$ \\
\hline $\mathrm{C} 13: 0$ & 0.19 & 0.10 & 0.005 & $<0.01$ & $<0.01$ & 0.02 \\
\hline $\mathrm{C} 14: 0$ iso & 0.08 & 0.06 & 0.017 & 0.47 & 0.10 & 0.95 \\
\hline C14:0 & 11.21 & 8.48 & 0.546 & $<0.01$ & 0.02 & 0.30 \\
\hline $\mathrm{C} 15: 0$ iso & 0.19 & 0.12 & 0.006 & $<0.01$ & 0.03 & 0.11 \\
\hline C15:0 anteiso & 0.39 & 0.27 & 0.025 & $<0.01$ & 0.55 & 0.84 \\
\hline C15:0 & 0.90 & 0.55 & 0.016 & $<0.01$ & 0.20 & 0.53 \\
\hline $\mathrm{C} 16: 0$ iso & 0.25 & 0.21 & 0.040 & 0.38 & 0.29 & 0.93 \\
\hline C16:0 & 25.99 & 22.96 & 0.421 & 0.02 & 0.17 & 0.23 \\
\hline $\mathrm{C} 17: 0$ & 0.64 & 0.37 & 0.012 & $<0.01$ & 0.13 & 0.61 \\
\hline C18:0 & 6.45 & 8.32 & 0.308 & $<0.01$ & $<0.01$ & 0.18 \\
\hline $\mathrm{C} 20: 0$ & 0.13 & 0.16 & 0.002 & $<0.01$ & $<0.01$ & $<0.01$ \\
\hline C21:0 & 0.04 & 0.03 & 0.002 & $<0.01$ & $<0.01$ & 0.35 \\
\hline \multicolumn{7}{|l|}{ Monounsaturated } \\
\hline C10:1 & 0.50 & 0.25 & 0.012 & $<0.01$ & 0.02 & $<0.01$ \\
\hline$c i s-9$ C14:1 & 0.24 & 0.16 & 0.008 & $<0.01$ & 0.03 & 0.81 \\
\hline trans $-9 \mathrm{C} 16: 1+\mathrm{C} 17: 0$ iso & 0.48 & 0.33 & 0.016 & $<0.01$ & $<0.01$ & $<0.01$ \\
\hline cis-7 C16:1 & 0.36 & 0.37 & 0.013 & 0.52 & $<0.01$ & 0.44 \\
\hline cis-9 C16:1 + C17:0 anteiso & 1.69 & 1.18 & 0.062 & $<0.01$ & 0.08 & 0.84 \\
\hline cis-9 C17:1 & 0.21 & 0.13 & 0.007 & $<0.01$ & $<0.01$ & 0.04 \\
\hline trans $6+7+8$ C18:1 & 0.33 & 1.39 & 0.069 & $<0.01$ & 0.75 & 0.40 \\
\hline trans-9 C18:1 & 0.29 & 1.19 & 0.114 & $<0.01$ & 0.28 & 0.21 \\
\hline trans-10 C18:1 & 0.78 & 3.90 & 0.510 & $<0.01$ & $<0.01$ & 0.02 \\
\hline trans-11 C18:1 & 1.71 & 1.42 & 0.198 & 0.19 & 0.05 & 0.05 \\
\hline trans-12 C18:1 & 0.40 & 0.84 & 0.071 & $<0.01$ & 0.07 & 0.07 \\
\hline cis-9 C18:1 & 14.95 & 23.64 & 0.475 & $<0.01$ & 0.53 & 0.21 \\
\hline trans $-15+$ cis-11 C18:1 & 0.58 & 0.84 & 0.037 & $<0.01$ & 0.08 & 0.24 \\
\hline cis-12 C18:1 & 0.27 & 0.14 & 0.009 & $<0.01$ & 0.84 & $<0.01$ \\
\hline cis-13 C18:1 & 0.09 & 0.11 & 0.011 & 0.05 & $<0.01$ & 0.02 \\
\hline trans $-16+$ cis-14 C18:1 & 0.35 & 0.27 & 0.020 & $<0.01$ & 0.02 & $<0.01$ \\
\hline cis-9 C20:1 & 0.08 & 0.03 & 0.003 & $<0.01$ & 0.15 & 0.35 \\
\hline \multicolumn{7}{|l|}{ Polyunsaturated } \\
\hline trans -9, trans -12 + other trans/trans $\mathrm{C} 18: 2$ & 0.39 & 0.37 & 0.017 & 0.45 & $<0.01$ & 0.97 \\
\hline cis- 9, trans -12 + other cis/trans $\mathrm{C} 18: 2$ & 0.25 & 0.24 & 0.011 & 0.32 & 0.02 & 0.52 \\
\hline trans -9, cis-12 C18:2 & 0.03 & 0.04 & 0.003 & 0.48 & 0.02 & 0.59 \\
\hline trans-11, cis-15 C18:2 & 0.04 & 0.17 & 0.060 & 0.07 & 0.06 & 0.09 \\
\hline cis-9, cis-12 C18:2 & 2.26 & 1.46 & 0.101 & $<0.01$ & $<0.01$ & 0.18 \\
\hline cis-9, trans-11 C18:2 & 0.96 & 0.61 & 0.149 & 0.05 & 0.07 & 0.03 \\
\hline trans-9, cis-11 C18:2 & 0.01 & 0.05 & 0.006 & $<0.01$ & $<0.01$ & $<0.01$ \\
\hline trans-10, cis-12 C18:2 & 0.01 & 0.02 & 0.002 & 0.04 & 0.05 & 0.78 \\
\hline trans-11, cis-13 C18:2 & 0.02 & 0.01 & 0.005 & 0.40 & 0.03 & 0.68 \\
\hline trans -11, trans $-13 \mathrm{C} 18: 2$ & 0.02 & 0.01 & 0.005 & 0.40 & 0.03 & 0.68 \\
\hline$\Sigma$ trans/trans $8,10-9,11-10,12$ & 0.01 & 0.02 & 0.001 & $<0.01$ & $<0.01$ & 0.18 \\
\hline cis -9, cis- 12, cis-15 C18:3 & 0.22 & 0.15 & 0.005 & $<0.01$ & $<0.01$ & 0.02 \\
\hline \multicolumn{7}{|l|}{ Ratios } \\
\hline $\mathrm{RA} / \mathrm{RA}+\mathrm{VA}^{3}$ & 0.362 & 0.321 & 0.0129 & 0.02 & $<0.01$ & 0.48 \\
\hline C14:1/C14:0 + C14:1 & 0.022 & 0.018 & 0.0010 & $<0.01$ & 0.03 & 0.92 \\
\hline $\mathrm{C} 16: 1 / \mathrm{C} 16: 0+\mathrm{C} 16: 1$ & 0.059 & 0.051 & 0.0013 & $<0.01$ & 0.04 & 0.71 \\
\hline C18:1/C18:0 + C18:1 & 0.706 & 0.728 & 0.0131 & 0.14 & 0.02 & 0.08 \\
\hline
\end{tabular}

${ }^{1}$ Refers to diets containing 0 (control) or $60 \mathrm{~g}$ of OO/kg of DM.

${ }^{2}$ Probability of significant effects due to diet supplementation with olive oil (D), time on diet (T), and their interaction $(\mathrm{D} \times \mathrm{T})$.

${ }^{3} \mathrm{RA}=$ rumenic acid, cis-9, trans-11 C18:2; VA = vaccenic acid, trans-11 C18:1. 


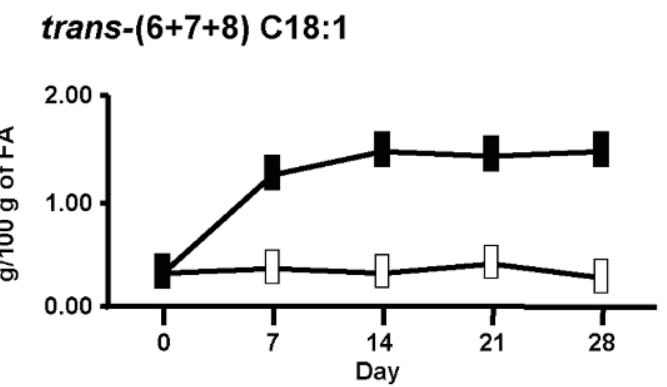

trans-10 C18:1

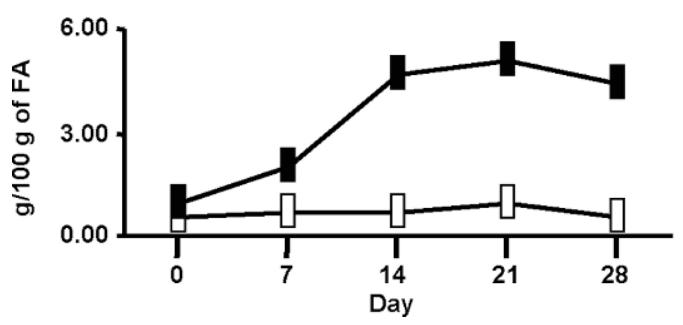

trans-9 C18:1

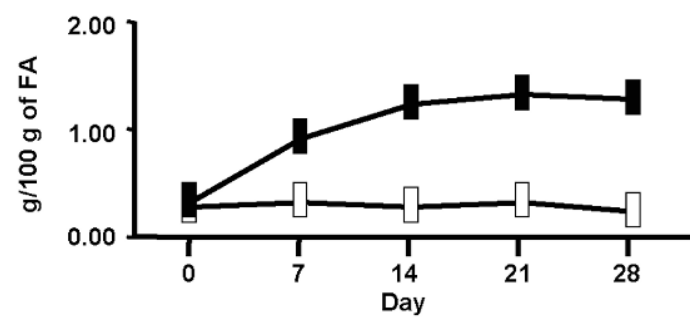

trans-11 C18:1

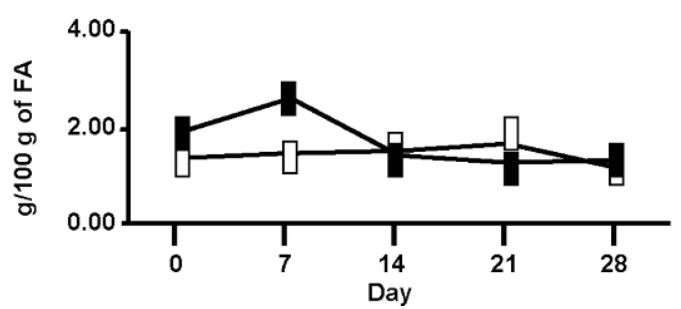

Figure 1. Temporal changes in trans $6+7+8 \mathrm{C} 18: 1$, trans-9 C18:1, trans-10 C18:1, and trans-11 C18:1 [g/100 g of fatty acids (FA)] in ewes fed diets containing $0(\square)$ or $60(\square) \mathrm{g}$ of olive oil/kg of DM. Values represent the mean from 2 lots of 6 animals per lot. SED $=0.069$, 0.114, 0.510, and 0.198 for trans 6+7+8 C18:1, trans-9 C18:1, trans-10 C18:1, and trans-11 C18:1, respectively.

by the mammary gland is desaturated to $c i s-9$ C18:1 (Lock and Garnsworthy, 2003).

The different ratios reported in Table 3 are commonly used as a proxy for $\Delta^{9}$-desaturase activity. In our study, all the ratios, with the exception of 18:1/18:0 + C18:1, were greater $(P<0.05)$ in milk from ewes fed unsupplemented diets. Similar results were also reported for dairy ewes fed a diet enriched with $4 \%$ soybean oil (Mele et al., 2006). The results observed for the C18:1/C18:0 + C18:1 ratio (Table 3) would be less reliable, because they could be greatly affected by the high intake of oleic acid as well as the biohydrogenation rates in the rumen. It seems more appropriate to trust the C14:1/C14:0 + C14:1 $\Delta^{9}$-desaturase index (which was reduced by the

Table 4. Mean effects of diet supplementation with olive oil (OO) on milk conjugated linoleic acid isomers profile $(\mathrm{mg} / \mathrm{g}$ of total fatty acids)

\begin{tabular}{|c|c|c|c|c|c|c|}
\hline \multirow[b]{2}{*}{ Item } & \multicolumn{2}{|c|}{ Treatment $^{1}$} & \multirow[b]{2}{*}{ SED } & \multicolumn{3}{|c|}{$P<^{2}$} \\
\hline & Control & $\mathrm{OO}$ & & $\mathrm{D}$ & $\mathrm{T}$ & $\mathrm{D} \times \mathrm{T}$ \\
\hline \multicolumn{7}{|c|}{ trans/trans } \\
\hline 12,14 & 0.063 & 0.065 & 0.0090 & 0.81 & 0.07 & 0.61 \\
\hline 11,13 & 0.040 & 0.038 & 0.0030 & 0.48 & 0.22 & 0.49 \\
\hline 10,12 & 0.023 & 0.027 & 0.0023 & 0.17 & 0.50 & 0.85 \\
\hline 9,11 & 0.102 & 0.087 & 0.0293 & 0.62 & 0.13 & 0.25 \\
\hline 8,10 & 0.032 & 0.039 & 0.0022 & 0.02 & 0.05 & 0.34 \\
\hline 7,9 & 0.051 & 0.035 & 0.0072 & 0.06 & $<0.01$ & 0.04 \\
\hline \multicolumn{7}{|c|}{ cis/trans + trans/cis } \\
\hline 12,14 & 0.010 & 0.018 & 0.0016 & $<0.01$ & $<0.01$ & 0.24 \\
\hline 11,13 & 0.013 & 0.008 & 0.0020 & 0.03 & 0.87 & 0.04 \\
\hline 10,12 & 0.020 & 0.063 & 0.0122 & $<0.01$ & 0.22 & 0.53 \\
\hline 9,11 & 8.688 & 3.859 & 1.3894 & 0.02 & 0.05 & 0.02 \\
\hline 8,10 & 0.243 & 0.110 & 0.0214 & $<0.01$ & 0.76 & 0.04 \\
\hline 7,9 & 0.774 & 1.988 & 0.3052 & $<0.01$ & 0.16 & 0.06 \\
\hline \multicolumn{7}{|l|}{ cis/cis } \\
\hline 9,11 & 0.024 & 0.018 & 0.0024 & 0.06 & 0.02 & 0.38 \\
\hline
\end{tabular}

${ }^{1}$ Refers to diets containing 0 (control) or $60 \mathrm{~g}$ of OO/kg of DM.

${ }^{2}$ Probability of significant effects due to diet supplementation with olive oil (D), time on diet (T), and their interaction $(\mathrm{D} \times \mathrm{T})$. 
OO treatment), because C14:1 is almost exclusively produced in the mammary gland from C14:0. An inhibitory effect of trans FA generated in the rumen on $\Delta^{9}$ activity may exist, because these FA are putative inhibitors of this enzyme (Chilliard and Ferlay, 2004), which may explain the lower levels of C14:1 and other cis-9 MUFA (Table 3) in OO-supplemented diets.

Previous accounts of oleic acid biohydrogenation by rumen microorganisms were generally depicted as a direct conversion of oleic to stearic acid without the formation of trans intermediates (Kellens et al., 1986). The sharp increase in trans-C18:1 content (Figure 1) in supplemented milk, however, would support more recent studies (Mosley et al., 2002; Proell et al., 2002) that oleic acid biohydrogenation in the rumen involves the formation of several positional isomers of trans monoenes rather than only direct biohydrogenation to form stearic acid. These in vitro experiments already indicated that oleic acid undergoes extensive isomerization by rumen microorganisms yielding several monoene positional isomers. Feeding high-oleic canola oil also resulted in greater concentrations of trans- 6 to trans-10 C18:1 compared with other diets in the rumen of lactating cows (Loor et al., 2002).

Among the trans monoenes, 2 specific isomers, 10 and 11, are of particular interest. Under most dietary conditions, VA is the major trans isomer produced during PUFA biohydrogenation (Chilliard and Ferlay, 2004). The pattern observed in the current study (Figure 1) could be attributed to different causes. Biohydrogenation pathways of oleic acid generate no RA and little VA (Mosley et al., 2002; Abu-Ghazaleh et al., 2005) and thus should not lead to enhanced VA concentrations in milk. Additionally, the increased concentration of trans-10 C18:1 with the intake of oleic acid found is further evidence that this isomer is primarily produced from isomerization of cis-9 C18:1 (Loor et al., 2002; Mosley et al., 2002) rather than from trans-10, cis-12 C18:2 (Harfoot and Hazlewood, 1997; Griinari and Bauman, 1999), because this pathway would require the presence of a high amount of linoleic acid as precursor.

The significant $\mathrm{D} \times \mathrm{T}$ interactions found for trans -10 and VA might be due to the sharp changes in the OOsupplemented animal milk fat observed during the second week of the supplementation, which then remained constant in the rest of the experiment (wk 3 and 4). In contrast, the lack of $\mathrm{D} \times \mathrm{T}$ interactions for some trans MUFA (6+7+8 and 9) would show a prompt response of these FA to OO supplementation during the first week and the persistence of this effect until the end of the experimental period. This different behavior might indicate that trans-FA C18:1 from $6+7+8$ and 9 would be the first products in the biohydrogenation pathway of the oleic acid, whereas other MUFA isomers, such as trans-10, would be formed later on.

\section{PUFA}

Decreases in linoleic acid levels can be partly justified because of their lower content in the OO-supplemented ration (Table 1). The decrease in RA content (Tables 3 and 4) should be attributed to the same reasons as the decrease in the VA percentage.

In contrast to RA, increases $(P<0.01)$ were observed for other CLA isomers. Enhanced trans-7, cis-9 positional isomer content in milk from ewes fed OO-supplemented rations is in agreement with studies on other ruminants. In a previous work (Collomb et al., 2004a), a highly significant correlation was also found between the daily intakes of oleic acid and the concentration of the CLA isomer trans-7, cis-9 in cow milk fat. The increase observed in this CLA isomer in ewe milk fat was closely associated with the rise in the peak where trans7 C18:1 eluted $\left(R^{2}=0.98 ; P<0.01\right)$. Corl et al. $(2002)$ demonstrated that the trans-7, cis-9 C18:2 in cow milk fat was derived almost exclusively from endogenous synthesis, whereas Piperova et al. (2002) found that virtually all of this CLA isomer in milk fat was produced postruminally via $\Delta^{9}$-desaturase. The precursor would be trans-7 C18:1 generated in the rumen.

The increase in trans-10, cis-12 and mainly trans-9, cis-11 (Tables 3 and 4) levels could be attributed to the shift in the rumen biohydrogenation pathways. In contrast to RA and trans-7, cis-9 C18:2, most CLA isomers found in milk appear to originate exclusively from rumen output. In dairy cows, diet-induced changes in trans-10, cis-12 have been well described (Griinari and Bauman, 1999), and more recent studies have reported sharp increases in trans-9, cis-11 C18:2 (Roy et al., 2006; Shingfield et al., 2006) in the milk of cows fed with different fat-enriched rations. Lactating ewes fed with $6 \%$ soybean oil in their rations and a similar forage:concentrate ratio also produced significant increases in milk trans-10, cis-12 and trans-9, cis-11 C18:2 content (Gómez-Cortés et al., 2008). This would support the argument that high fat content in diet together with a low forage:concentrate ratio could induce changes in the rumen biohydrogenation pathways.

The less remarkable amounts observed for trans-10, cis-12 C18:2 compared with trans-9, cis-11 C18:2 could be justified because of the biohydrogenation pathway of that CLA isomer. Its precursor would be linoleic acid (Griinari and Bauman, 1999), whose content is lower in the supplemented ration than in the control diet (Table 1). On the other hand, the pathway of trans-9, cis-11 C18:2 formation still remains unclear. The high correlation observed between the content of this CLA 
isomer and trans-10 C18:1 $(r=0.93 ; P<0.01)$ could be evidence of a common intermediate in the biohydrogenation pathways for both unsaturated FA, coinciding with previous studies on cow milk (Gama et al., 2008). However, this potential intermediate has not been identified and is still unknown.

The significant $\mathrm{D} \times \mathrm{T}$ interactions observed for some CLA isomers (Tables 3 and 4) indicate that the effect of OO supplementation on the rumen biohydrogenation pathways was not constant throughout the period of supplementation, which may be related to changes in the rumen environment.

\section{CONCLUSIONS}

Overall, OO supplementation substantially modified dairy ewe milk FA profile without any negative effects on animal performance. Results from this experiment support the idea that biohydrogenation pathways of cis9 C18:1 in the rumen involve the formation of stearic acid as well as relevant amounts of a variety of trans monoene C18:1, except for VA. This coincides with previous evidence obtained in in vitro studies. The generation of greater amounts of trans-7, cis-9 C18:2 coupled with lower levels of RA would result from changes in the rumen biohydrogenation pathways caused by a lipid supplementation richer in oleic acid and poorer in linoleic acid, whereas increases in trans-9, cis-11 C18:2 could be associated with the high proportion of concentrate and unprotected oil in the diet.

\section{ACKNOWLEDGMENTS}

This work was supported by the Ministerio de Educación y Ciencia (Spain; Research Projects AGL200504760 and Consolider CSD2007-063) and the Comunidad Autónoma de Madrid (Project S-0505/AGR/ 000153). We wish to thank M. V. Rodríguez-Pino (Instituto del Frío, Consejo Superior de Investigaciones Científicas) and N. Castañares, J. López, and O. LópezCampos (Estación Agrícola Experimental, Consejo Superior de Investigaciones Científicas) for their valuable technical assistance.

\section{REFERENCES}

Abu-Ghazaleh, A. A., M. B. Riley, E. E. Thies, and T. C. Jenkins. 2005. Dilution rate and $\mathrm{pH}$ effects on the conversion of oleic acid to trans C18:1 positional isomers in continuous culture. J. Dairy Sci. 88:4334-4341.

AOAC. 2006. Official Methods of Analysis of the Association of Official Agricultural Chemists. 18th ed. 1st rev. AOAC Int., Gaithersburg, MD.

Broudiscou, L., S. Pochet, and C. Poncet. 1994. Effect of linseed oil supplementation on feed degradation and microbial synthesis in the rumen of ciliate-free and refaunated sheep. Anim. Feed Sci. Technol. 49:189-202.
Chilliard, Y., and A. Ferlay. 2004. Dietary lipids and forages interactions on cow and goat milk fatty acid composition and sensory properties. Reprod. Nutr. Dev. 44:467-492.

Chilliard, Y., A. Ferlay, J. Rouel, and G. Lamberet. 2003. A review of nutritional and physiological factors affecting goat milk lipid synthesis and lipolysis. J. Dairy Sci. 86:1751-1770.

Chiofalo, B., L. Liotta, A. Zumbo, and V. Chiofalo. 2004. Administration of olive cake for ewe feeding: Effect on milk yield and composition. Small Rumin. Res. 55:169-176.

Collomb, M., R. Sieber, and U. Bütikofer. 2004a. CLA isomers in milk fat from cows fed diets with high levels of unsaturated fatty acids. Lipids 39:355-364.

Collomb, M., H. Sollberger, U. Bütikofer, R. Sieber, W. Stoll, and W. Schaeren. 2004b. Impact of a basal diet of hay and fodder beet supplemented with rapeseed, linseed and sunflowerseed on the fatty acid composition of milk fat. Int. Dairy J. 14:549-559.

Corl, B. A., L. H. Baumgard, J. M. Griinari, P. Delmonte, K. M. Morehouse, M. P. Yurawecz, and D. E. Bauman. 2002. Trans-7, cis-9 CLA is synthesized endogenously by $\Delta^{9}$-desaturase in dairy cows. Lipids 37:681-688.

Dhiman, T. R., S. H. Nam, and A. L. Ure. 2005. Factors affecting conjugated linoleic acid content in milk and meat. Crit. Rev. Food Sci. Nutr. 45:463-482.

Fay, L., and U. Richli. 1991. Location of double bonds in polyunsaturated fatty acids by gas chromatography-mass spectrometry after 4,4-dimethyloxazoline derivatization. J. Chromatogr. 541:89-98.

Gama, M. A. S., P. C. Garnsworthy, J. M. Griinari, P. R. Leme, P. H. M. Rodrigues, L. W. O. Souza, and D. P. D. Lanna. 2008. Dietinduced milk fat depression: Association with changes in milk fatty acid composition and fluidity of milk fat. Livest. Sci. 115:319-331.

Gaynor, P. J., R. A. Erdman, B. B. Teter, J. Sampugna, A. V. Capuco, D. R. Wald, and M. Hamosh. 1994. Milk fat yield and composition during abomasal infusion of cis and trans octanodecenoates in Holstein cows. J. Dairy Sci. 77:157-165.

Goering, M. K., and P. J. Van Soest. 1970. Forage Fiber Analysis (Apparatus, Reagents, Procedures and Some Applications). Agriculture Handbook No. 379. ARS-USDA, Washington, DC.

Gómez-Cortés, P., P. Frutos, A. R. Mantecón, M. Juárez, M. A. de la Fuente, and G. Hervás. 2008. Milk production, conjugated linoleic acid content, and in vitro ruminal fermentation in response to high levels of soybean oil in dairy ewe diet. J. Dairy Sci. 91:1560-1569.

Griinari, J. M., and D. E. Bauman. 1999. Biosynthesis of conjugated linoleic acid and its incorporation into meat and milk in ruminants. Pages 180-200 in Advances in Conjugated Linoleic Acid Research. Vol. 1. M. P. Yurawecz, M. M. Mossoba, J. K. G. Kramer, M. W. Pariza, and G. J. Nelson, ed. AOCS Press, Champaign, IL.

Harfoot, C. G., and G. P. Hazlewood. 1997. Lipid metabolism in the rumen. Pages 382-426 in The Rumen Microbial Ecosystem. P. M. Hobson, ed. Elsevier, New York, NY.

ISO-IDF. 2002. Milk Fat-Preparation of Fatty Acid Methyl Esters. International Standard ISO 15884-IDF 182:2002.

Jaros, D., W. Ginzinger, E. Tschager, R. Leitgeb, and H. Rohm. 2001. Application of oilseed feeding to reduce firmness of hard cheeses produced in the winter feeding period. Int. Dairy J. 11:611-619.

Jenkins, T. C. 1993. Lipid metabolism in the rumen. J. Dairy Sci. 76:3851-3863.

Kellens, M. J., H. L. Goderis, and P. P. Tobback. 1986. Biohydrogenation of unsaturated fatty acids by a mixed culture of rumen microorganisms. Biotechnol. Bioeng. 28:1268-1276.

Lock, A. L., and P. C. Garnsworthy. 2003. Seasonal variation in milk conjugated linoleic acid and $\Delta^{9}$-desaturase in dairy cows. Livest. Prod. Sci. 79:47-59.

Lock, A. L., B. M. Teles, J. W. Perfield II, D. E. Bauman, and L. A. Sinclair. 2006. A conjugated linoleic acid supplement containing trans-10 cis-12 reduces milk fat synthesis in lactating sheep. J. Dairy Sci. 89:1525-1532.

Lock, A. L., C. Tyburczy, D. A. Dwyer, K. J. Harvatine, F. Destaillats, Z. Mouloungui, L. Candy, and D. E. Bauman. 2007. Trans-10 octadecenoic acid does not reduce milk fat synthesis in dairy cows. J. Nutr. 137:71-76. 
Loor, J. J., A. B. P. A. Bandara, and J. H. Herbein. 2002. Characterization of 18:1 and 18:2 isomers produced during microbial biohydrogenation of unsaturated fatty acids from canola and soya bean oil in the rumen of lactating cows. J. Anim. Physiol. Anim. Nutr. (Berl.) 86:422-432.

Luna, P., M. Juárez, and M. A. de la Fuente. 2005. Validation of a rapid milk fat separation method to determine the fatty acid profile by gas chromatography. J. Dairy Sci. 88:3377-3381.

Mele, M., A. Buccioni, F. Petacchi, A. Serra, S. Banni, M. Antongiovanni, and P. Secchiari. 2006. Effect of forage/concentrate ratio and soybean oil supplementation on milk yield, and composition from Sarda ewes. Anim. Res. 55:273-285.

Mir, P. S., M. Ivan, M. L. He, B. Pink, E. Okine, L. Goonewardene, T. A. McAllister, R. Weselake, and Z. Mir. 2003. Dietary manipulation to increase conjugated linoleic acids and other desirable fatty acids in beef: A review. Can. J. Anim. Sci. 83:673-685.

Mosley, E. E., G. L. Powell, M. B. Riley, and T. C. Jenkins. 2002. Microbial biohydrogenation of oleic acid to trans isomers in vitro. J. Lipid Res. 43:290-296.

Palmquist, D. L., A. D. Beaulieu, and D. M. Barbano. 1993. Feed and animal factors influencing milk fat composition. J. Dairy Sci. 76:1753-1771.

Piperova, L. S., J. Sampugna, B. B. Teter, K. F. Kalscheur, M. P. Yurawecz, Y. Ku, K. Morehouse, and R. A. Erdman. 2002. Duodenal and milk trans octadecenoic acid and conjugated linoleic acid (CLA) isomers indicate postabsorptive synthesis is the predominant source of cis-9 containing CLA in lactating dairy cows. J. Nutr. 132:1235-1241.
Proell, J. M., E. E. Mosley, G. L. Powell, and T. C. Jenkins. 2002. Isomerization of stable isotopically labeled elaidic acid to cis and trans monoenes by ruminal microbes. J. Lipid Res. 43:2072-2076.

Pulina, G., A. Nudda, G. Battacone, and A. Cannas. 2006. Effects of nutrition on the contents of fat, protein, somatic cells, aromatic compounds, and undesirable substances in sheep milk. Anim. Feed Sci. Technol. 131:255-291.

Roy, A., K. J. Shingfield, and Y. Chilliard. 2006. Examination of the persistency of milk fatty acid composition responses to plant oils in cows given different basal diets, with particular emphasis on trans-C18:1 fatty acids and isomers of conjugated linoleic acid. Anim. Sci. 82:479-492.

Sanz-Sampelayo, M. R., Y. Chilliard, P. Schmidely, and J. Boza. 2007. Influence of type of diet on the fat constituents of goat and sheep milk. Small Rumin. Res. 68:42-63.

Shingfield, K. J., C. K. Reynolds, G. Hervás, J. M. Griinari, A. S. Grandison, and D. E. Beever. 2006. Examination of the persistency of milk fatty acid composition responses to fish oil and sunflower oil in the diet of dairy cows. J. Dairy Sci. 89:714-732.

Van Soest, P. J., J. B. Robertson, and B. A. Lewis. 1991. Methods for dietary fiber, neutral detergent fiber and non-starch polysaccharides in relation to animal nutrition. J. Dairy Sci. 74:35833597.

Walker, G. P., F. R. Dunshea, and P. T. Doyle. 2004. Effects of nutrition and management on the production and composition of milk fat and protein: A review. Aust. J. Agric. Res. 55:1009-1028.

Wang, Z., and L. A. Goonewardene. 2004. The use of MIXED models in the analysis of animal experiments with repeated measures data. Can. J. Anim. Sci. 84:1-11. 